\title{
Expression of genes FOLR1, BAG1 and LAPTM4B in functioning and non-functioning pituitary adenomas
}

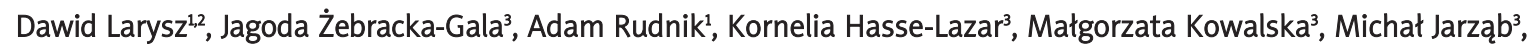 \\ Aleksandra Król3, Sylwia Szpak-Ulczok ${ }^{3}$, Piotr Bażowski', Barbara Jarząb \\ 1Department of Neurosurgery, Medical University of Silesia in Katowice, 2Department of Radiotherapy, Maria Skłodowska-Curie \\ Memorial Cancer Centre and Institute of Oncology, Gliwice Branch, ${ }^{3}$ Department of Nuclear Medicine and Endocrine Oncology, \\ Maria Skłodowska-Curie Memorial Cancer Center and Institute of Oncology, Gliwice Branch, Poland
}

\begin{abstract}
Introduction: The mechanism of pathogenesis of adenomas pituitary is still unknown; differences between pituitary cells of different origin are observed. Identification of genes specific to pituitary adenomas should give better understanding of differences in their response to therapy, especially to radiotherapy. The aim of our study was to independently validate differences in the expression of FOLR1, BAG1, LAPTM4B between functioning (FA) and non-functioning (NFA) pituitary adenomas reported by microarray-based studies.

Material and methods: Analysis of gene expression was performed by real-time quantitative PCR (QPCR) in 76 pituitary adenomas, 25 functioning and 51 non-functioning ones. The expression of the examined genes was normalized to the reference index, obtained by calculation of the geometric mean of reference genes expression: GUS-B, B2M, ACTB, EIF3S10, UBE2D2 and ATP6V1E.

Results: Two genes showed significant differences in expression between non-functioning adenomas and functioning ones (FA) (FOLR1 32.4 x greater $p=0.022$, BAG1 $2.2 \times$ lower $p=0.0002)$. The expression of LAPTM4B $(1.1 \times$ lower) was only insignificantly changed. The expression of FOLR1 in all tumours (functioning and non-functioning) was higher in older patients (over 50 years of age) ( $p=0.018)$. Expression of BAG1 was significantly lower in older patients $(p=0.015)$. In a subgroup of pure non-functioning adenomas there was a higher expression of FOLR1 in older patients $(p=0.006)$. Analysis of expression profiles and invasiveness of tumours did not reveal any significant differences both in non-functioning and functioning tumours.

Conclusions: Among pituitary adenomas, the highest level of expression FOLR1 is seen in NFA which are negative by immunohistochemistry to all pituitary hormones while GH-producing adenomas are the only class of pituitary tumours where FOLR1 expression is virtually absent. For BAG1 we confirm a significantly higher expression in functioning (both $P R L$ and GH producing) adenomas than non-functioning ones, while LAPTM4B does not exhibit any expression changes between different classes of pituitary tumours.
\end{abstract}

Key words: pituitary adenoma, gene expression, real-time quantitative PCR.

Communicating author:

Dawid Larysz, MD, PhD, MSc, Department of Neurosurgery, Medical University of Silesia in Katowice, ul. Medyków 14, 40-752 Katowice, phone +48 3278945 03, fax +48 3229289 25, e-mail: dawilar@gmail.com 


\section{Introduction}

Adenomas of the anterior pituitary lobe are the most frequent disorders in the hypothalamic-pituitary system and account for approximately $10 \%$ of intracranial tumours (the prevalence of these tumours in autopsy series is reported to be 5-20\%) [1,16]. Pituitary tumours represent a very interesting model: they share the properties of well-differentiated endocrine tissue, able to secrete hormones characteristic of the cells of origin, and the invasive growth ability, characteristic of malignant cells.

Within pituitary tumours there is a wide variety of phenotypes, including both non-functioning adenomas and hormone-producing tumours. Until now, immunohistochemical tests have constituted the main way to distinguish these entities. There is little specific knowledge about the molecular processes differentiating subtypes of pituitary tumours, especially considering the fact that the general cancer pathways may be not involved as from the pathological point of view, pituitary tumours are benign adenomas.

Until the last decade, there were two prevailing theories about the origin of pituitary tumours. Earlier it was implied that pituitary tumours originated as a result of continuing stimulation by a hypothalamic hormone or factor. The more recent theory, favoured by most authors, is related to somatic mutations in pituitary cells and does not exclude the synergistic influence of these two mechanisms [1]. It is widely accepted that pituitary tumours are monoclonal in origin, thus tumours arise as a consequence of a single cell mutation followed by clonal expansion [1,21]. The initiating event of pituitary neoplasia can be activation of an oncogene or/and inactivation of a tumour suppressor gene, followed by a multi-step process which involves cell proliferation, differentiation and hormone production. The activation of the oncogene is a dominant event and even a single allele alteration will lead to a change in cellular function. Such event is observed in about $40 \%$ of GH adenomas, $10 \%$ of non-functioning tumours (NF) and $6 \%$ of ACTH adenomas as a point mutation in the Gs- $\alpha$ gene which leads to an increased GTP-ase activity and oversecretion of GH and ACTH [9]. Other oncogenes involved in pituitary tumorigenesis are cyclin D1 (CCND1, considered specific to NF adenomas) [10], H-RAS (characteristic of PRL adenomas) [2] and C-MYC (found in GH, PRL, ACTH and NF adenomas) $[2,5,23]$.
Tumour suppressor inactivation is recessive and both alleles of the gene must be affected to influence cellular events or function. The inactivation of tumour suppressor genes is found in different loci in various pituitary adenomas. One of the most known ones is multiple endocrine neoplasia type 1 (MEN1) gene, located on chromosome 11, whereas in sporadic tumours, deletions in different regions of chromosome 11 and 9 have been found [1]. There is still little specific knowledge about the molecular processes differentiating subtypes of pituitary tumours. Only few microarray analyses of pituitary adenomas have been performed until now. They resulted in specification of a large number of molecular markers $[6,17,18]$, including folate receptor (FOLR1), BCL2-associated athanogene (BAG1) and lysosomal protein transmembrane 4 beta (LAPTM4B). These genes were validated both by QPCR (and immunohistochemistry in the case of FOLR1) but only by the same authors [5]. FR $\alpha$ seems to be one of the most promising epithelial cancer markers for targeted imaging and therapy and many imaging and therapeutic methods based on FR $\alpha$ have been developed $[3,4,12,15,22,25]$. Our study was intended to provide an independent validation for studies concerning an abnormal expression of FOLR1, BAG1 and LAPTM4B genes in pituitary adenomas. The main aim was to analyze differences in the gene expression between functioning (FA) and non-functioning (NFA) pituitary adenomas.

\section{Material and methods}

The study was approved by the Ethic Committee of Maria Sklodowska-Curie MSC Cancer Center and Institute of Oncology in Gliwice.

\section{Group of patients}

The studied group of patients consisted of 37 women and 39 men. Mean age was 53.7 years (16-73 years) for a female subgroup and 52.1 years (24-77 years) for men. The group of patients was additionally divided into two subgroups according to age. The first subgroup of patients below 50 years of age consisted of 11 women and 15 men. The older subgroup, over 50 years of age consisted of 26 women and 24 men.

Increased features of invasiveness mean the presence of tumour cells in samples of dura obtained during the surgery, in a histopathological examination. Moreover, all aforementioned tumours infiltrate lateral walls of the sella, so they were classified as III or IV 
Table I. Clinical characteristics of patients

\begin{tabular}{|lcc|}
\hline Clinical data & Number of patients & Percent \\
\hline Age $<50$ years & 26 & $34.21 \%$ \\
\hline Age $>50$ years & 50 & $65.79 \%$ \\
\hline Invasive tumours & 13 & $17.10 \%$ \\
\hline Non-invasive tumours & 63 & $82.90 \%$ \\
\hline Primary surgery & 64 & $84.21 \%$ \\
\hline Reoperations & 12 & $15.79 \%$ \\
\hline
\end{tabular}

degree in Knosp's Classification of Cavernous Sinus Invasion. In 12 cases, a surgical resection was performed as a reoperation. In 6 cases, surgery was the first reoperation. 2 patients were operated on previously twice. 4 cases were operated previously four times, and one patient had a seventh surgery. Only two patients with multiple surgeries (first reoperation) had functioning adenomas, both with clinical symptoms of acromegaly. Detailed clinical information is shown in Table I.

\section{Tumours}

The analysis of gene expression was carried out in 76 samples of pituitary adenomas collected during transsphenoidal surgery performed in the Department of Neurosurgery of Silesian Medical University in Katowice. Intraoperatively, fragments of pituitary adenomas were taken and stored in RNA later at $4^{\circ} \mathrm{C}$. All adenomas were histopathologically verified. Detailed histopathological findings as judged by postoperative immunohistochemistry (IHC) are shown in Table II. ' 0 ' adenomas means negative immunohistochemistry towards the previous hormones. The GH and PRL adenomas were grouped as functioning adenomas (FA) due to the clinical symptoms caused, while LH, FSH and ' 0 ' adenomas were described clinically as non-functioning tumours (NFA).

\section{Isolation of RNA}

Total RNA was extracted from homogenised frozen tissue using Mini Kits (Qiagen), which included a DNAse step. RNA quantity was measured by NanoDrop ND-1000 mini-spectrophotometer and quality was estimated by Agilent 2100 using RNA 6000 Nano Assay (Agilent Technologies). RNA integrity, assessed by RIN index (Agilent 2100), was within the 4.5-9.1 range.
Table II. Immunohistochemical data of collected samples of pituitary adenomas

\begin{tabular}{|lcl|}
\hline TICH result & Number of patients & Percent \\
\hline GH & 9 & $11.84 \%$ \\
\hline PRL & 16 & $21.05 \%$ \\
\hline LH & 24 & $31.58 \%$ \\
\hline FSH & 5 & $6.58 \%$ \\
\hline "O” & 22 & $28.95 \%$ \\
\hline Total FA & 25 & $32.89 \%$ \\
\hline Total NFA & 51 & $67.11 \%$ \\
\hline
\end{tabular}

\section{cDNA synthesis}

cDNA was synthesised from 500 ng of total RNA by Omniscript Kit (Qiagen), with a mixture of oligodT and random nonamer primers (Sigma) and $10 \mathrm{U}$ RNAse inhibitor (Sigma). The reaction was done in $37^{\circ} \mathrm{C}$ for 1 hour.

Quantitative real-time reverse transcription-PCR (QPCR):

Analysis of gene expression was performed by realtime quantitative PCR with the use of fluorescent probes (Universal Probe Library, Roche). Amplicons were designed using a Web-based application (www.rocheapplied-science.com/sis/rtpcr/upl) (Table I). QPCR was carried out in a 96-well optical reaction plate using an ABI Prism 7700 Sequence Detection System (Applied Biosystems). Five microlitres of template cDNA (equivalent to $500 \mathrm{ng}$ of total RNA) were added to $15 \mu \mathrm{l}$ of PCR reaction mix containing $10 \mu \mathrm{l}$ TaqMan Universal PCR Master Mix (Applied Biosystems), $1 \mu \mathrm{l}$ forward and reverse primers (200 nM), $1 \mu$ l probe (100 nM) and water. Thermal cycling conditions were as follows: $50^{\circ} \mathrm{C}$ for 2 min (incubation and activation AmpErase UNG), $95^{\circ} \mathrm{C}$ for $10 \mathrm{~min}$ (activation AmpliTag Polymerase DNA), $95^{\circ} \mathrm{C}$ for $15 \mathrm{sec}$ (denaturation) and $60^{\circ} \mathrm{C}$ for $1 \mathrm{~min}$ (annealing and extension). Every sample was examined twice. The standard curve, used in experiments, was prepared from serial dilutions of human reference RNA (Stratagene). Expression of the examined genes was normalized to the reference index, obtained by calculation of a geometric mean of reference genes expression: ACTB, EIF3S10, ATP6V1E, UBE2D2, B2M and GUS B.

\section{Statistical analysis}

The geNorm application software for Microsoft Excel was used to identify the most stable reference gene 
under the described conditions and to determine the optimal number of reference genes required for reliable normalization of QPCR data.

To determine between-group differences, we used Mann-Whitney nonparametric test. Differences were considered significant at $p<0.05$. The fold change was calculated by dividing medians of expression.

\section{Results}

The result of FOLR1, BAG1 and LAPTM4B gene expression analysis was first analyzed as raw data (Ct values), then gene expression was normalized with relation to the reference index, obtained by calculation of the geometric mean of reference genes expression: ACTB, EIF3S10, ATP6V1E, UBE2D2, B2M and GUS B.

We observed significant differences in gene expression in particular types of pituitary adenomas (Table II). When we compared pure non-functioning adenomas (" $O$ ") and functioning ones (FA), 2 genes showed significant differences in expression between groups (FOLR1 32.4x $\uparrow p=0.022$, BAG1 2.2x $\downarrow p=0.0002$ ). The expression of LAPTM4B $(1.1 \times \downarrow)$ was only insignificantly changed.

The same direction of changes was stated when all clinically non-functioning adenomas ("O", $\mathrm{LH}+, \mathrm{FSH}+$ ) were compared to functioning $(\mathrm{GH}+, \mathrm{PRL}+)$ ones. FOLR1 expression was significantly higher $(42 x, p=0.006)$ in NFA, BAG1 was significantly lower $(2 x, p=0.004)$ and no significant change was observed for LAPTM4B.

When all particular types of adenomas were compared to "O" adenomas, FOLR1 was significantly lower (145.7x) in GH adenomas, while a 1.8-fold increase of BAG1 expression was observed $(p=0.004)$ (Fig. 1). Analysis of PRL-omas showed a significant difference only for BAG1 (2.4x $\uparrow, p=0.001)$. We did not observe any statistically significant differences in the expression of FOLR1 and LAPTM4B in comparison of LH and " 0 " adenomas. Only BAG1 was overexpressed (1.2x $\uparrow$, $p=0.047)$ in LH as compared to " 0 ". There were no significant changes in the expression of investigated genes between FSH and "O" tumours. When GH and PRL tumours were compared, no significant difference was observed.

Taking into account the age of patients we found out that the expression of FOLR1 in all tumours (functioning and non-functioning) was higher in older patients (over 50 years of age) $(p=0.018)$. Expression of BAG1 was significantly lower in older patients $(p=0.015)$. We did not find any significant difference in the expression of LAPTM4B according the age of patients (Fig. 2). In a subgroup of pure non-functioning adenomas we also found out a higher expression of FOLR1 in older patients $(p=0.006)$. Analysis of expression profiles and invasiveness of tumours did not reveal any significant differences both in non-functioning and functioning tumours.

\section{Discussion}

Our study was intended to validate and extend the earlier results of microarray-based studies by Evans et al. [5], Moreno et al. [17] and Morris et al. [18], which indicated significant changes in the expression of FOLR1, BAG1 and LAPTM4B in non-functioning pituitary adenomas as compared to normal pituitary. We analyzed the expression of these genes by real time PCR and compared to functioning adenomas producing $\mathrm{GH}$ and/or PRL. Also, we evaluated an expression of the three genes in different kinds of clinically non-functioning pituitary tumours: adenomas negative by $\mathrm{IHC}$ to all investigated hormones "O", $\mathrm{LH}+$ and/or FSH+ tumours (the last two considered as NFA+ tumours). Indeed, our analysis, performed on a large and independent clinical material, confirmed the overexpression of FOLR1 in non-functioning adenomas and of BAG1 in functioning adenomas, while changes in LAPTM4B appeared to be not significant.

The first results indicating FOLR1 overexpression in NFAs originate from Evans et al. study who used a cDNA array that contained 7075 genes to compare the expression profile of a normal pituitary sample to single cases of non-functioning pituitary adenoma (NF), and $\mathrm{GH}$, prolactin (PRL)- and adrenocorticotropin (ACTH)secreting adenomas [8]. The folate receptor was significantly overexpressed in clinically non-functioning (NF) adenomas but not in functioning adenomas (producing adrenocorticotropic hormone, growth hormone, or prolactin) or normal pituitary tissue. This result was confirmed by them in 32 pituitary adenomas by QPCR. FOLR1 showed a 2-30-fold increase of expression in $70 \%$ of non-functioning pituitary adenomas in comparison to normal pituitary samples and 2-10-fold decrease in GH adenomas and 2-100-fold in PRL adenomas. Liu et al. examined the expression of FR $\alpha$ mRNA in 76 pituitary adenomas and 7 normal pituitary glands. Expression of FR $\alpha$ mRNA and protein was uniquely overexpressed in immunohistochemically positive 
FOLR1

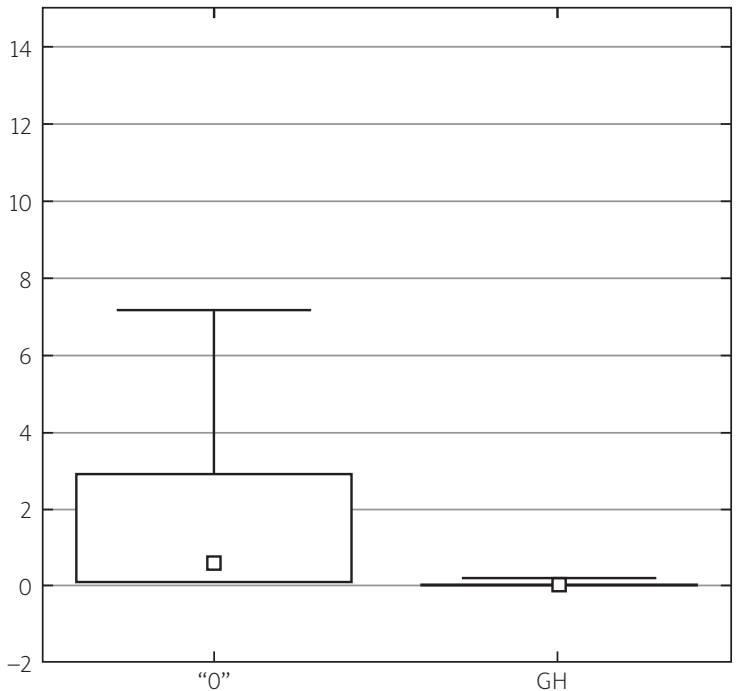

FOLR1

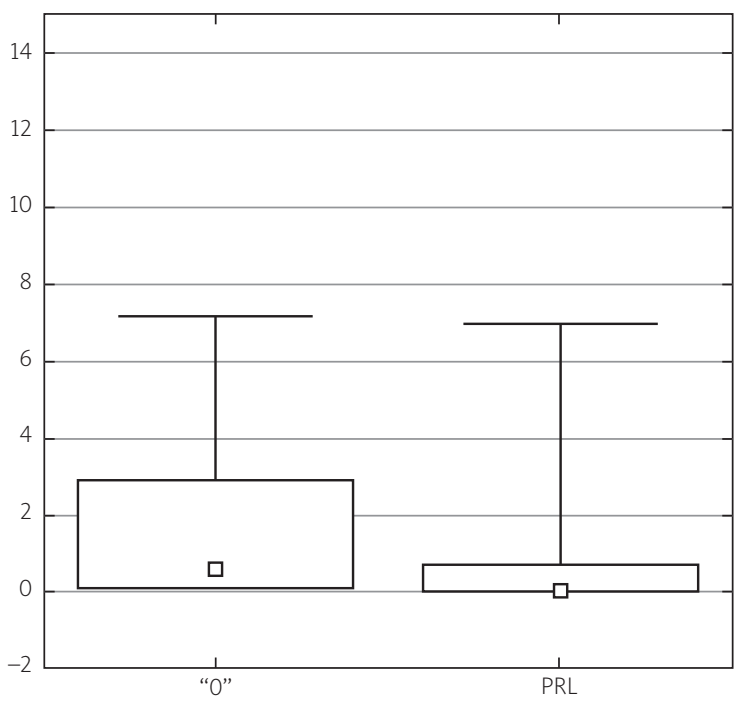

$B A G 1$

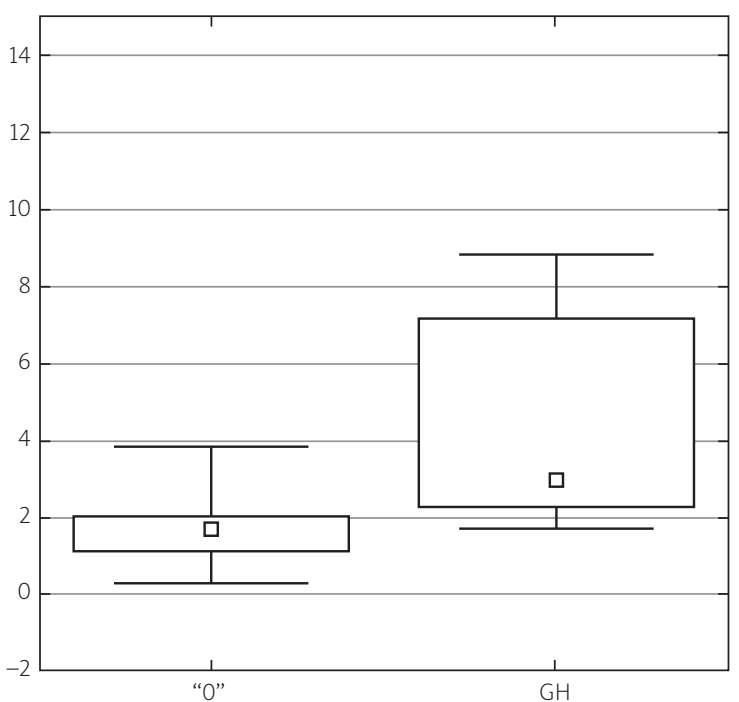

$B A G 1$

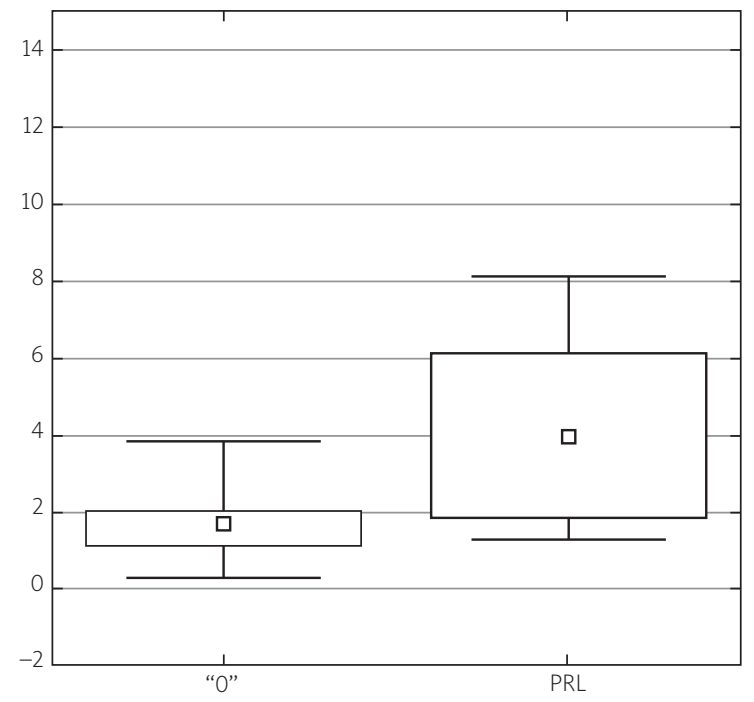

Fig. 1. Comparison of FOLR1 and BAG1 expression in GH or PRL $(n=25)$ to IHC negative ("O") ( $n=51)$ pituitary adenomas. (U Mann Whitney test, $p$ value for FOLR1 (GH vs. "0") $p=0.012$ (PRL vs. "0") ns, for BAG1 (GH vs. "O”) $p=0.004$ (PRL vs. "0") $p=0.001$ ).

and negative non-functioning adenomas but not in functioning adenomas (adrenocorticotropic hormone, growth hormone, and prolactin) or normal pituitary tissues. The expression of FR $\alpha$ was positively correlated with tumour invasiveness, size and Ki-67 LI in NFs [15].
In our study, a significant increase of FOLR1 expression was observed in " 0 " and all clinically non-functioning adenomas in comparison to FA. Additionally, we did not observe statistically significant differences in the FOLR1 expression in LH and FSH adenomas in 
FOLR 1

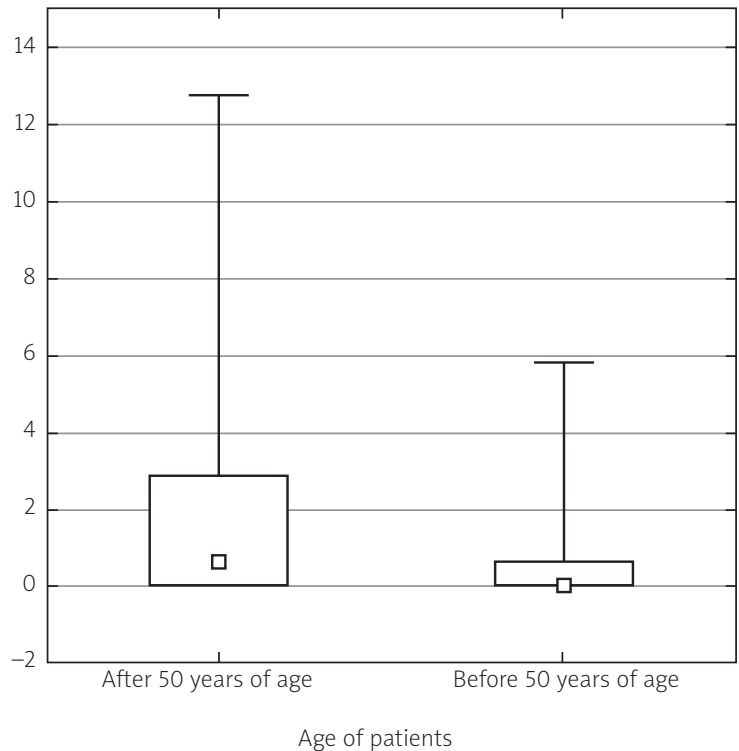

LAPTMB4

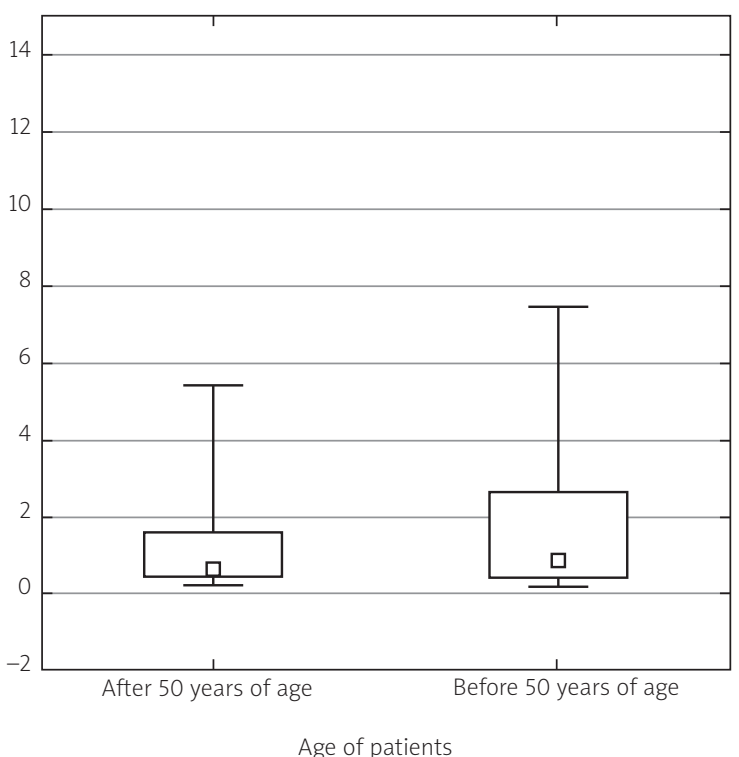

BAG1

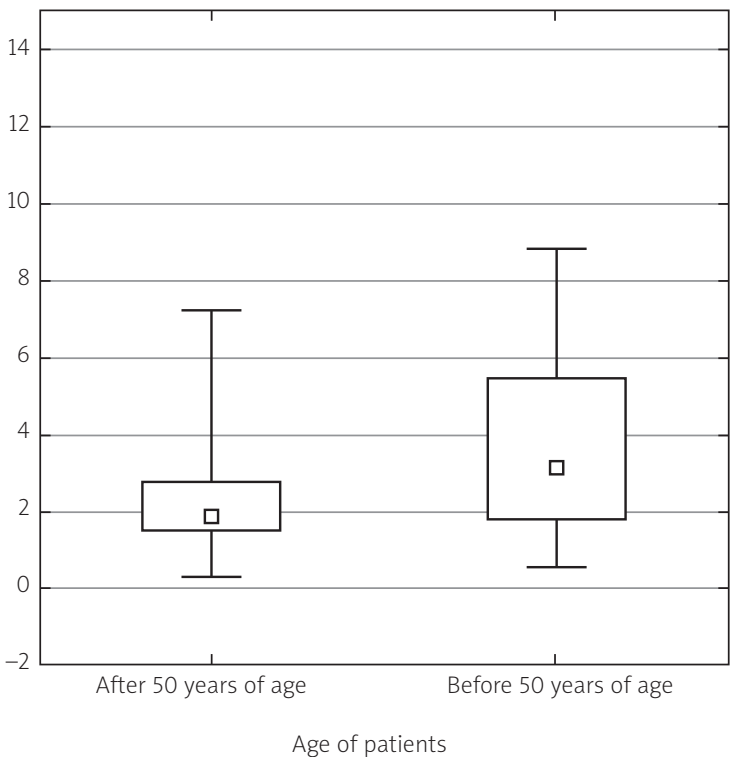

Age of patients

$$
\begin{aligned}
& \text { Median } \\
& \square \text { 25-75\% } \\
& \text { 工 Min-Max }
\end{aligned}
$$

Fig. 2. Comparison of FOLR1, BAG1 expression in studied patients according to age. Subgroup below 50 years old $n=26$, older subgroup $n=50$. ( $U$ Mann Whitney test, $p$ value for FOLR1 $p=0.018$, for BAG1 $p=0.015$, for LAPTM4B ns).

comparison to "0" adenomas. The significant value of our study is the observation that the expression of FOLR1 was virtually absent in GH producing adenomas. We did not perform any comparison to normal pituitaries which are to be taken from post mortem dissection, thus, the available biologic material is not fully comparable to fresh frozen tumours, taken intraoperatively. We did not perform any functional studies either but the results demonstrated by Evans indicated that overexpression of FOLR1 mRNA by NF pituitary adenomas resulted in production of properly folded folate receptor ( $F R \alpha)$ protein, which might 
Table III. Primers and probes used for quantitative real-time PCR measurement of analyzed genes

\begin{tabular}{|c|c|c|c|c|c|c|}
\hline Gene & Name & Gene ID & Primer $\mathrm{F}$ sequence & Primer R sequence & Probe & $\begin{array}{l}\text { Probe } \\
\text { sequence }\end{array}$ \\
\hline \multicolumn{7}{|c|}{ Investigated genes } \\
\hline FOLR1 & $\begin{array}{l}\text { Homo sapiens } \\
\text { folate receptor } 1\end{array}$ & NM_000802 & GAGGACAAGTTGCATGAGCA & GTTGGTAGAACAGCAGGCATT & 65 & CTGGAGGA \\
\hline BAG1 & $\begin{array}{l}\text { Homo sapiens } \\
\text { BCL2-associated } \\
\text { athanogene }\end{array}$ & NM_004323.2 & GCCACAATAGAGCAGTTTATGAAG & TGAAATTTTCTGGCAGGATCA & 25 & TGGAGGAG \\
\hline LAPTM4B & $\begin{array}{l}\text { Homo sapiens } \\
\text { lysosomal } \\
\text { associated } \\
\text { protein trans- } \\
\text { membrane } 4 \text { beta }\end{array}$ & NM_018407 & ACTCCATTCAGGAATACATACGG & ATGACATCATCTCTGTAGGGAAAA & 16 & CTGCCTCC \\
\hline \multicolumn{7}{|c|}{ Reference genes } \\
\hline ACTB & $\beta$-actin & NM_001101.2 & ATTGGCAATGAGCGGTTC & GGATGCCACAGGACTCCAT & 11 & CTTCCAGC \\
\hline ATP6V1E1 & $\begin{array}{l}\text { ATPase, } \mathrm{H}+ \\
\text { transporting, } \\
\text { lysosomal } 31 \mathrm{kDa} \text {, } \\
\text { V1 subunit E1 }\end{array}$ & NM_001696.2 & AAGCCGGCTGGATCTCAT & GCATTTGCACCAAACAAGG & 3 & CCCAGCAG \\
\hline$B 2 M$ & $\beta$-2-microglobulin & NM_004048.2 & TTCTGGCCTGGAGGCTATC & TCAGGAAATTTGACTTTCCATTC & 42 & CATCCAGC \\
\hline EIF3S10 & $\begin{array}{l}\text { Eukaryotic } \\
\text { translation } \\
\text { initiation } \\
\text { factor 3, } \\
\text { subunit } \\
10 \text { theta }\end{array}$ & NM_003750.1 & AGTAGAGCGCCTGTACCATGA & GCGTGTATTGGAGGCAGAAT & 61 & TTGCCCAG \\
\hline GUSB & $\beta$-glucuronidase & NM_000181.1 & CGCCCTGCCTATCTGTATTC & TCCCCACAGGGAGTGTGTAG & 57 & CTGGGGCC \\
\hline UBE2D2 & $\begin{array}{l}\text { Ubiquitin- } \\
\text { conjugating } \\
\text { enzyme E2D } 2\end{array}$ & NM_003339.2 & AATGGCAGCATTTGTCTTGA & CACAACAGAGAACAGATGGACAA & 67 & CTCCAGCA \\
\hline
\end{tabular}

mediate vitamin transport, and could potentially facilitate the growth of these tumours [12]. Moreover, in our study we did not reveal any significant differences in expression profiles concerning invasiveness and recurrence both in non-functioning and functioning tumours. These findings are contrary to results of Liu [15]. Comparison of expression profiles of aforementioned genes in infiltrated dura samples and in adenomas without tendency to invasiveness in a larger group of invasive adenomas, probably could reveal more detailed explanation.

$\mathrm{FR} \alpha$ is a high affinity folate transporter that is overexpressed by many cancers and could provide a growth advantage to cells that express it as folic acid plays an important role in cellular growth and development. Analysis of FR $\alpha$ expression by Western blotting confirmed that $F R \alpha$ protein was specifically overexpressed in NF tumours [12]. The folic acid receptor is absent or rarely expressed in normal tissues, and its expression is increased in ovarian [19], breast, renal and colorectal carcinomas [5]. High affinity and selective overexpression of FOLR1 for folate in non-functioning pituitary adenomas provide a new opportunity for direct chemotherapy and radioimmunotherapy of these tumours by direct or indirect binding of various drugs to folic acid. This possibility is considered in some 
Dawid Larysz, Jagoda Żebracka Gala, Adam Rudnik, Kornelia Hasse-Lazar, Małgorzata Kowalska, Michał Jarząb, Aleksandra Król, Sylwia Szpak-Ulczok, Piotr Bażowski, Barbara Jarząb

Table IV. FOLR1, BAG1 and LAPTM4B expression in different types of pituitary adenomas

\begin{tabular}{|c|c|c|c|c|c|c|c|c|c|}
\hline & Number & Median & Quartile 1 & Quartile 3 & Skewness & Kurtosis & $\begin{array}{c}\text { Comparison } \\
\text { FA/NFA }\end{array}$ & $\begin{array}{c}\text { Comparison } \\
\text { of each class } \\
\text { to ' } 0 \text { ' }\end{array}$ & $\begin{array}{c}\text { Comparison } \\
\text { of NFA+ to } \\
\text { NFA 'O' }\end{array}$ \\
\hline \multicolumn{10}{|c|}{ FOLR1 } \\
\hline $\mathrm{FA}^{*}$ & 25 & 0.018 & 0.002 & 0.104 & 2.793 & 7.175 & & $p=0.022$ & \\
\hline $\mathrm{NFA}^{\star}$ & 51 & 0.814 & 0.011 & 2.897 & 2.018 & 5.333 & $p=0.006$ & & \\
\hline $\mathrm{GH}$ & 9 & 0.004 & 0.002 & 0.01 & 2.788 & 7.943 & & $p=0.01$ & \\
\hline PRL & 16 & 0.281 & 0.004 & 0.688 & 2.06 & 3.29 & & NS & \\
\hline $\mathrm{LH}$ & 24 & 0.965 & 0.009 & 3.492 & 2.068 & 5.031 & & NS & \\
\hline $\mathrm{FSH}$ & 5 & 1.449 & 0.023 & 1.739 & 0.748 & 0.008 & & NS & NS \\
\hline “0” & 22 & 0.583 & 0.06 & 2.897 & 1.235 & 0.597 & & & \\
\hline \multicolumn{10}{|c|}{$B A G 1$} \\
\hline FA & 25 & 3.724 & 1.858 & 6.076 & 0.406 & -1.288 & & $p=0.0002$ & \\
\hline NFA & 51 & 1.813 & 1.369 & 2.765 & 1.232 & 1.542 & $p=0.004$ & & \\
\hline $\mathrm{GH}$ & 9 & 2.979 & 2.251 & 7.188 & 0.515 & -1.669 & & $p=0.003$ & \\
\hline PRL & 16 & 3.921 & 1.805 & 6.066 & 0.315 & -1.272 & & $p=0.001$ & \\
\hline $\mathrm{LH}$ & 24 & 2.022 & 1.576 & 3.51 & 0.956 & 0.211 & & $p=0.047$ & \\
\hline FSH & 5 & 2.026 & 0.872 & 2.569 & -0.033 & -2.299 & & NS & NS \\
\hline “0” & 22 & 1.676 & 1.092 & 1.999 & 0.754 & 0.338 & & & \\
\hline \multicolumn{10}{|c|}{ LAPTM4B } \\
\hline FA & 25 & 0.772 & 0.446 & 2.6 & 1.646 & 2.748 & NS & NS & \\
\hline NFA & 51 & 0.539 & 0.336 & 1.335 & 2.831 & 8.878 & & & \\
\hline $\mathrm{GH}$ & 9 & 1.801 & 0.321 & 2.094 & 0.15 & -1.589 & & NS & \\
\hline PRL & 16 & 0.747 & 0.449 & 2.857 & 1.551 & 1.715 & & NS & \\
\hline $\mathrm{LH}$ & 24 & 0.546 & 0.347 & 1.519 & 2.691 & 7.638 & & NS & NS \\
\hline FSH & 5 & 0.355 & 0.183 & 0.522 & 0.764 & -0.206 & & NS & \\
\hline “0” & 22 & 0.735 & 0.354 & 1.317 & 2.286 & 5.317 & & & \\
\hline
\end{tabular}

$F A$ - functioning adenomas, "O" - null cell adenomas, GH - somatotropinomas, PRL - prolactinomas, $L H, F S H$ - gonadotropic adenomas, $F A^{\star}-G H+, P R L+$ adenomas

$N F A^{*}$ - "O", $L H+, F S H+$ adenomas

other cancers but has not still found any application in NF pituitary adenomas [14].

The second gene analyzed in our study is $\mathrm{Bcl}-2$ associated athanogene (BAG1), an anti-apoptotic protein found at high levels in a number of human cancers, which has been reported by Morris et al. to be over-expressed both in functioning and non-functioning adenomas [18]. We observed statistically significant differences in BAG1 expression between functioning and non-functioning adenomas. BAG1 was significantly overexpressed in GH and PRL adenomas as compared to "O" tumours. Also LH producing adenomas exhibited 
a significantly higher level of BAG1 transcript in comparison to "0" tumours. The highest level of expression was observed in PRL-omas. Evans et al. in 2008, published the results of expression profiling and proteomics analyses of six prolactinomas and eight normal pituitary tissue samples. They found out an increased expression of the survival factor BAG1 and Pit-1 transcription factor but a decreased E-cadherin and $\mathrm{N}$-cadherin expression in PRL adenomas [7]. Recent studies have shown that BAG1 is rarely expressed in normal tissue, but highly expressed in breast cancer [24], lung cancer [20] or colon cancer [13]. Probably BAG1 protein can be positively associated with proliferation, infiltration and metastasis of tumour cells. BAG1 interacts not only with $\mathrm{Bcl}-2$ but also with other different target molecules such as HSP70, and RAF-1 and regulates growth and survival of tumour cells. It is possible that an increase of BAG1 expression can repress apoptosis and stimulate tumorigenesis.

The reciprocal overexpression of FOLR1 and BAG1 (the last one less expressed in ' 0 ' adenomas) indicates that the mechanisms of the participation of both genes in neoplastic transformation are different in functioning and non-functioning adenomas. Prospective studies are necessary to relate both genes to prognosis of pituitary adenomas.

Lysosomal-associated protein transmembrane4-b (LAPTM4B), a novel gene upregulated in hepatocellular carcinoma [11], was reported to be significantly over-expressed in adrenocorticotropin (ACTH)-secreting adenomas and non-functioning pituitary adenomas (NFA) in comparison to normal pituitary samples, by Morris et al. who used the Affymetrix GeneChip HG-U133A arrays. Our QPCR-based analysis does not confirm differential changes of this gene in any kind of pituitary adenomas.

\section{Conclusions}

Among pituitary adenomas investigated, the highest level of expression of folate receptor $\alpha$ mRNA (FOLR1) is seen in non-functioning adenomas which are negative by immunohistochemistry to all pituitary hormones while $\mathrm{GH}$ producing adenomas are the only class of pituitary tumours where FOLR1 expression is virtually absent.

For BAG1 gene (Bcl2 associated athanogene) we show a significantly higher expression in functioning (both PRL and GH producing) adenomas than non-functioning ones, while LAPTM4B does not exhibit expres- sion changes between different classes of pituitary tumours.

In older patients, over 50 years of age, we found out a higher expression of FOLR1 both in the NF group and the whole group of patients. On the other hand, a higher expression of BAG1 gene was found with the younger age of patients. We did not reveal any correlations between expression profiles of analyzed genes with invasiveness of pituitary adenomas.

\section{Acknowledgement}

Ministry of Science and Higher Education grant No: 2946/P01/2006/31.

\section{References}

1. Arafah BM, Nasrallah MP. Pituitary tumors: pathophysiology, clinical manifestations and management. Endocr Relat Cancer 2001; 8: 287-305.

2. Asa SL, Ezzat S. Genetics and proteomics of pituitary tumors. Endocrine 2005; 28: 43-47.

3. Clifton GT, Sears AK, Clive KS, Holmes JP, Mittendorf EA, Ioannides CG, Ponniah S, Peoples GE. Folate receptor $\alpha$ : a storied past and promising future in immunotherapy. Hum Vaccin 2011; 7 : 183-190.

4. Elnakat $H$, Ratnam M. Role of folate receptor genes in reproduction and related cancers. Front Biosci 2006; 11: 506-519.

5. Evans CO, Moreno CS, Zhan X, McCabe MT, Vertino PM, Desiderio DM, Oyesiku NM. Molecular pathogenesis of human prolactinomas identified by gene expression profiling, RT-qPCR, and proteomic analyses. Pituitary 2008; 11: 231-245.

6. Evans CO, Reddy P, Brat DJ, O’Neill EB, Craige B, Stevens VL, Oyesiku NM. Differential expression of folate receptor in pituitary adenomas. Cancer Res 2003; 63: 4218-4224.

7. Evans CO, Yao C, Laborde D, Oyesiku NM. Folate receptor expression in pituitary adenomas cellular and molecular analysis. Vitam Horm 2008; 79: 235-266.

8. Evans CO, Young AN, Brown MR, Brat DJ, Parks JS, Neish AS, Oyesiku NM. Novel patterns of gene expression in pituitary adenomas identified by complementary deoxyribonucleic acid microarrays and quantitative reverse transcription-polymerase chain reaction. J Clin Endocrinol Metab 2001; 86: 3097-3107.

9. Farrell WE, Clayton RN. Epigenetic change in pituitary tumorigenesis. Endocr Relat Cancer 2003; 10: 323-330.

10. Farrell WE, Clayton RN. Molecular pathogenesis of pituitary tumors. Front Neuroendocrinol 2000; 21: 174-198.

11. Kasper G, Vogel A, Klaman I, Gröne J, Petersen I, Weber B, Castaños-Vélez E, Staub E, Mennerich D. The human LAPTM4b transcript is upregulated in various types of solid tumours and seems to play a dual functional role during tumour progression. Cancer Lett 2005; 224: 93-103.

12. Kelemen LE. The role of folate receptor alpha in cancer development, progression and treatment: cause, consequence or innocent bystander? Int J Cancer 2006; 119: 243-250. 
Dawid Larysz, Jagoda Żebracka Gala, Adam Rudnik, Kornelia Hasse-Lazar, Małgorzata Kowalska, Michał Jarząb, Aleksandra Król, Sylwia Szpak-Ulczok, Piotr Bażowski, Barbara Jarząb

13. Kikuchi R, Noguchi T, Takeno S, Funada Y, Moriyama H, Uchida Y. Nuclear BAG-1 expression reflects malignant potential in colorectal carcinomas. Br J Cancer 2002; 87: 1136-1139.

14. Leamon CP, Reddy JA. Folate-targeted chemotherapy. Adv Drug Deliv Rev 2004; 56: 1127-1141

15. Liu X, Ma S, Yao Y, Li G, Feng M, Deng K, Dai C, Cai F, Li Y, Zhang B, Wang R. Differential Expression of Folate Receptor Alpha in Pituitary Adenomas and Its Relationship to Tumor Behavior. Neurosurgery 2012; 70: 1274-1280.

16. Molitch ME, Russell EJ. The pituitary incidentaloma. Ann Intern Med 1990; 312: 1364-1370.

17. Moreno CS, Evans CO, Zhan X, Okor M, Desiderio DM, Oyesiku NM. Novel molecular signaling and classification of human clinically nonfunctional pituitary adenomas identified by gene expression profiling and proteomic analyses. Cancer Res 2005; 65: 10214-10222.

18. Morris DG, Musat M, Czirjak S, Hanzély Z, Lillington DM, Korbonits M, Grossman AB. Differential gene expression in pituitary adenomas by oligonucleotide array analysis. Eur J Endocrinol 2005; 153: 143-151.

19. Peters DG, Kudla DM, DeLoia J, Chu TJ, Fairfull L, Edwards RP, Ferrell RE. Comparative Gene Expression Analysis of Ovarian Carcinoma and Normal Ovarian Epithelium by Serial Analysis of Gene Expression. Cancer Epidemiol Biomarkers Prev 2005; 14: 1717-1723.

20. Rorke S, Murphy S, Khalifa M, Chernenko G, Tang SC. Prognostic significance of BAG-1 expression in nonsmall cell lung cancer. Int J Cancer 2001; 95: 317-322

21. Schittenhelm J, Psaras T, Meyermann R, Honegger J, Beschorner R. Pituitary adenomas and craniopharyngiomas are CDX2 negative neoplasms. Folia Neuropathol 2010; 48: 75-80.

22. Spannuth WA, Sood AK, Coleman RL. Farletuzumab in epithelial ovarian carcinoma. Expert Opin Biol Ther 2010; 10: 431-437.

23. Suhardja A, Kovacs K, Rutka J. Genetic basis of pituitary adenoma invasiveness: A review. J Neurooncol 2001; 52: 195-204.

24. Townsend PA, Dublin E, Hart IR, Kao RH, Hanby AM, Cutress RI, Poulsom R, Ryder, K, Barnes DM, Packham G. BAG-1 expression in human breast cancer: interrelationship between BAG-1 RNA, protein, HSC70 expression and vZhao X, Li H, Lee RJ. Targeted drug delivery via folate receptors. Expert Opin Drug Deliv 2008; 5: 309-319. 